Journal of Korean Powder Metallurgy Institute

Vol. 9 , No. 6,2002

\title{
Nanodispersion-Strengthened Metallic Materials
}

\author{
Thomas Weissgaerber, Christa Sauer* and Bernd Kieback \\ Fraunhofer Institute for Manufacturing and Advanced Materials \\ Powder Metallurgy and Composite Materials Dresden Winterbergstr. 28, 01277 Dresden \\ *Dresden University of Technology; Institute for Materials Science Mommsenstr. 13, 01062 Dresden \\ (Received 30 October 2002 ; Accepted form 5 December 2002)
}

\begin{abstract}
Dispersions of non-soluble ceramic particles in a metallic matrix can enhance the strength and heat resistance of materials. With the advent of mechanical alloying it became possible to put the theoretical concept into practice by incorporating very fine particles in a fairly uniform distribution into often oxidation- and corrosionresistant metal matrices, e.g. superalloys. The present paper will give an overview about the mechanical alloying technique as a dry, high energy ball milling process for producing composite metal powders with a fine controlled microstructure. The common way is milling of a mixture of metallic and nonmetallic powders (e.g. oxides, carbides, nitrides, borides) in a high energy ball mill. The heavy mechanical deformation during milling causes also fracture of the ceramic particles to be distributed homogeneously by further milling. The mechanisms of the process are described. To obtain a homogeneous distribution of nano-sized dispersoids in a more ductile matrix (e.g. aluminiumor copper based alloys) a reaction milling is suitable. Dispersoids can be formed in a solid state reaction by introducing materials that react with the matrix either during milling or during a subsequent heat treatment. The pre-conditions for obtaining high quality materials, which require a homogeneous distribution of small dispersoids, are: milling behaviour of the ductile phase ( $\mathrm{Al}, \mathrm{Cu}$ ) will be improved by the additives (e.g. graphite), homogeneous introduction of the additives into the granules is possible and the additive reacts with the matrix or an alloying element to form hard particles that are inert with respect to the matrix also at elevated temperatures. The mechanism of the in-situ formation of dispersoids is described using copper-based alloys as an example. A comparison between the in-situ formation of dispersoids (TiC) in the copper matrix and the milling of $\mathrm{Cu}-\mathrm{TiC}$ mixtures is given with respect to the microstructure and properties, obtained.
\end{abstract}

Keywords: Dispersions-Strengthened Material, Nano-sized dispersoid, Mechanical alloying, Creep strength

\section{Introduction}

The development of dispersion strengthened (DS) alloys by internal oxidation in $1930^{1)}$ and the invention of dispersion strengthened aluminium (SAP) in 19492) led to a strong interest in using the potential of dispersion strengthening for other alloy systems. Experimental facts about DS metals stimulated a number of theoretical investigations of dispersion strengthening at high homologous temperatures. The theoretical consideration done by Orowan ${ }^{3)}$ results in a critical stress for a dislocation to bypass a dispersoid leaving behind a dislocation loop around the dispersoid ${ }^{4)}$ which is given in its simplest form by

$$
\sigma_{O R}=\frac{0,8 G b M}{L}
$$

where $G$ is the shear modulus, $b$ is the Burgers vector, $\mathrm{M}$ is the Taylor factor and $\mathrm{L}$ is the interdispersoid distance. The interdispersoid distance is given by

$$
L=\left[(\pi / f)^{0.5}-2\right](2 / 3)^{0,5} r
$$

where $\mathrm{f}$ is the dispersoid volume fraction and $\mathrm{r}$ is the dispersoid radius. Eq. 1 and Eq. 2 clearly show that it is essential to distribute the dispersoids finely and evenly in order to obtain a strong alloy. Significant increase in room temperature strength due to the addition of dispersoids may be obtained in alloys which exhibit a small interdispersoid spacing (e.g. 50-100 nm). 
Moreover, distributing a given volume fraction of dispersoids more finely is more effective than increasing the volume fraction because of the square root dependence of Eq. 2.

Simple mechanical mixing of powders produces a material with a homogeneity depending on starting powder particle size. Internal Oxidation or selective reduction is limited, from thermodynamic considerations, to simple alloy systems. Chemical co-precipitation of fine dispersoids and matrix powders did meet the requirements for dispersion strengthening, demonstrated by the commercial introduction of TD- $\mathrm{Ni}^{5}$ ) followed by TD-NiCr. ${ }^{6)}$ Although, the production cost of the materials was high and there are limitations in the selection of alloying elements. The technical breakthrough for dispersion strengthened materials came in the form of mechanical alloying (MA) process discovered by Benjamin. ${ }^{7)}$ The MA process overcame the metallurgical problems associated with the incorporation of nanometer-sized dispersoids and the restrictions in the material selection. The process allows also the use of reactive elements such as $\mathrm{Al}$ and $\mathrm{Ti}$ to produce the full range of oxide-dispersion strengthened (ODS) superalloys. Moreover, the MA process has led to the production of other materials, such as dispersion strengthened light alloys (Al based), dispersion strengthened copper and silver, including the synthesis of alloys (e.g. intermetallics) or composite materials.

The present paper will focus on the illustration of the MA process in order to prepare advanced materials with an optimised microstructure and dispersion strengthening effect.

\section{Experimental Procedure}

\subsection{The Mechanical Alloying process}

\subsubsection{Basic mechanisms}

Mechanical Alloying is a dry-milling method for processing composite powders with a controlled microstructure. The process was originally developed to produce Ni-based ODS superalloys. ${ }^{7}$ Applying the MA process as a solid state process material limitations can be overcome and alloys from normally incompatible systems such as oxide-metal systems, immiscible liquids, intermetallics and metastable phases (e.g. amorphous phases) can be produced. Several types of high energy ball mills (e.g. planetary ball mill, attritor, vibratory mills) can be used for mechanical alloying. Unlike the machinery used for comminution, the ratio of balls to powder in mechanical alloying is relatively high. The ratio ranges from 6 to 1 by weight to as high as 30 to 1 , but most commonly are ranges 10 to 1 to 20 to 1 . The diameter of the balls may range from 4 to $30 \mathrm{~mm}$ but are usually 8 to $10 \mathrm{~mm}$ and normally balls are made of steel. The milling atmosphere consists of either nitrogen or argon. Liquids can also be used.

A general description of the MA process and the mechanisms is given in. ${ }^{7-11)}$ A mixture of metal or master alloy powder and nonmetal powder is charged into a suitable high-energy ball mill. During each collision of the grinding balls, a multitude of powder particles is trapped along the line of centres. These particles undergo severe plastic deformation, which increases their surface to volume ratio and ruptures the surface films of adsorbed contaminants. Where metal particles overlap, atomically clean metal interfaces are brought into intimate contact, forming cold welds and building up composite metal particles consisting of various combinations of the starting powder mixture. With continued plastic deformation, the hardness of the powder increases, and fracturing and cold welding occur simultaneously. A balance is achieved between the rate of welding, which tends to increase the average composite particle size, and the rate of fracturing, which tends to decrease the average composite particle size. With continued processing, this leads to a steadystate particle size distribution of the composite metal particles. The permanent interplay between welding and fracturing establishes a kneading action that continues to refine the internal structures of the composite metal powders. Beside the structural refinement a true alloying occurs during milling and the dispersoid powders (e.g. yttria for ODS Ni-based superalloys) are reduced in size and uniformly distributed in the metallic matrix.

2.1.2 Reaction milling and in-situ formation of dispersoids

The milling behaviour of ductile materials is characterised by a rapid particle coarsening in the case of $\mathrm{Al}$ or $\mathrm{Cu}$. The introduction of suitable nano-sized dispersoids, e.g. $\mathrm{Al}_{2} \mathrm{O}_{3}$, TiC or $\mathrm{Y}_{2} \mathrm{O}_{3}$, in the metallic matrix is impossible due to strong welding of the powder particles. To obtain a homogeneous distribution of nanosized dispersoids in such a ductile matrix a reaction milling is suitable. Reaction milling, developed by Jangg et al., ${ }^{12-14)}$ is a variant of mechanical alloying, which has been established mainly for the production 
of homogeneous alloys or alloys with an amorphous structure but also for the manufacture of dispersion strengthened alloys. Suitable dispersoids can be formed by a solid state reaction by introducing components that react with the matrix either during milling or during a subsequent heat treatment. In the case of $\mathrm{Al}$ alloys the introduction of graphite was most successful. The carbon introduced by milling reacts with $\mathrm{Al}$ to form fine and well distributed $\mathrm{Al}_{4} \mathrm{C}_{3}$ particles. The reaction rate depends on the type of carbon used. Practically no $\mathrm{Al}_{4} \mathrm{C}_{3}$ is generated during milling using graphite. C containing compounds such as stearic acid react still more with Al during milling; complete reaction is however attained after a subsequent heat treatment. ${ }^{15}$ ) $\mathrm{Al}_{4} \mathrm{C}_{3}$ exhibits high hardness and shear strength, is practically insoluble in $\mathrm{Al}$ even close to the melting point and therefore does not tend to coarsen during thermal exposure of the dispersion hardened product.

The TiC formation during milling and subsequent thermal treatment of mechanically alloyed $\mathrm{Cu}-\mathrm{Ti}-\mathrm{C}$ powder blends is described in. ${ }^{16)}$ The mechanical alloying was carried out in order to prepare TiC dispersion strengthened copper. A high milling energy is necessary in order to obtain predominant $\mathrm{TiC}$ formation during milling. In contrast, mechanical alloying at low milling energy leads to a supersaturated $\mathrm{Cu}(\mathrm{Ti})$ solid solution with incorporated nanometer sized amorphous graphite particles. To form nanometer sized TiC dispersoids during subsequent heating of the milled granules a size reduction of graphite during milling is necessary. The size of the carbide particles therefore directly depends on the size of the graphite particles.

During the heat treatment of the milled powders the $\mathrm{Cu}(\mathrm{Ti})$ solid solution dissolve and titanium segregates at the $\mathrm{Cu}(\mathrm{Ti}) / \mathrm{C}$ interface and leads to a heterogeneous nucleation of $\mathrm{TiC}$ at the interface. The precipitates of the equilibrium phase $\beta-\mathrm{Cu}_{4} \mathrm{Ti}$ formed at low temperatures in the matrix dissolve with increasing temperature and the complete formation of $\mathrm{TiC}$ is observed. The microstructure of these alloys after hot extrusion is microcrystalline with incorporated homogeneously distributed TiC dispersoids with a mean diameter of $15 \mathrm{~nm} .{ }^{17,18}$ )

2.2. Consolidation and thermomechanical processing of MA powders

Fig. 1 shows schematically the process path from raw material to final product in the case of ODS superalloys. Generally, the MA powders are consolidated either by hot extrusion or by hot isostatic pressing obtaining a fully dense material. This operation yields a monolithic bar with an extremely fine grain size (less than $0.5 \mu \mathrm{m}$ ), which depends on the dispersoid size and volume fraction. During the working process to create the final form, a thermo-mechanical treatment is integrated in order to adjust the microstructure and the properties of the material. This step results in an increase in grain growth and grain aspect ratio. Grain aspect ratios may be as high as 10 to 1 in order to obtain highly creep resistant alloys.

\section{Results and Discussion}

\subsection{ODS superalloys by MA}

Today there are two manufacturers of oxide dispersion strengthened Ni-based superalloys: Inco Alloys Int., Inc. and Plansee GmbH Lechbruck. The main strengthening factor is the addition of small amounts of yttria (1vol.-\% - 2.5 Vol.-\%) which is milled into

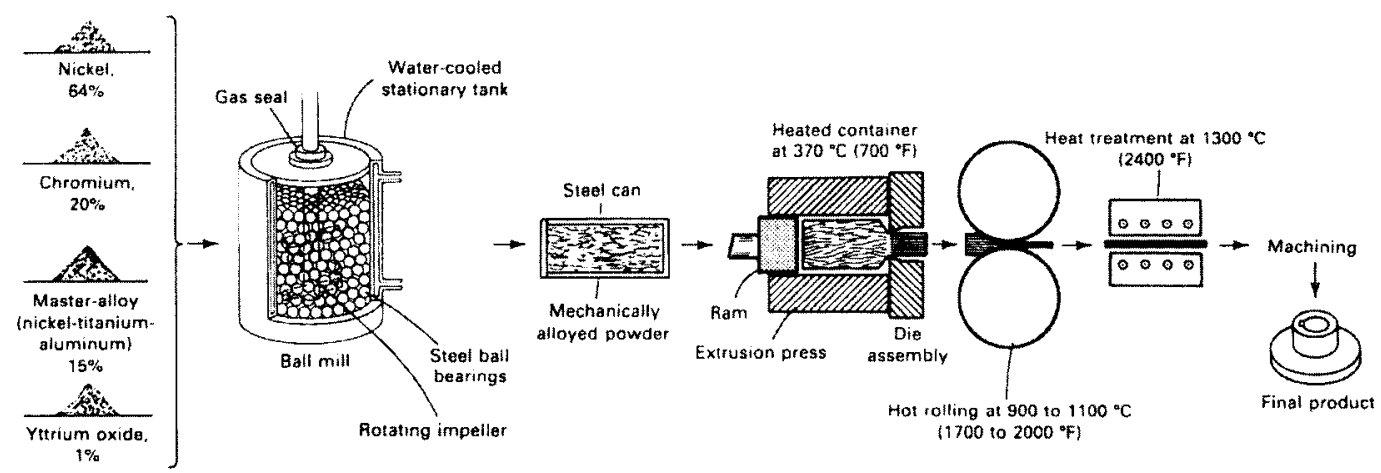

Fig. 1. Schematic diagram showing the processing from raw materials to final products made from ODS superalloys. ${ }^{8}$ 
the NiCr (MA754 from Inco and PM1000 from Plansee) or NiCrAl metal matrix (MA6000 from Inco and PM 3030 from Plansee). Due to the increased Al- and Ti-content in MA6000 and PM3030 the formation of cuboidal, coherent $\mathrm{N}_{\mathrm{i} 3} \mathrm{Al}\left(\gamma^{\prime}\right)$ particles leads to the precipitation hardening effect additionally to the dispersion hardening. A significant strengthening effect of the $\gamma^{\prime}$-particles is obtained at low temperatures $(600$ $900^{\circ} \mathrm{C}$ ). At higher temperatures $\left(\mathrm{T}>900^{\circ} \mathrm{C}\right)$ a continuous decay of the creep strength in MA6000 due to the $\gamma^{\prime}$ coarsening and raft formation is obtained Fig. 2 .

Typical fields of applications of ODS Ni-based superalloys are space and aerospace engineering and the glass processing industry.

\subsection{Dispersion strengthened Aluminium alloys} by MA

The $\mathrm{Al}_{4} \mathrm{C}_{3}$ dispersion strengthened aluminium alloys with the tradename DISPAL prepared by "Reaction Milling"12-14) have been jointly developed by Krebsöge, Erbslöh-Aluminium and Eckart-Werke. ${ }^{20)}$ The process generally leads to materials with excellent high temperature properties Fig. 3 and thermal shock resistance and high sound damping capacity. The materials can be used in combustion engines (e.g. motor cycle pistons). Some problems arise from the economics of DISPAL materials. The price is acceptable only for some specific applications.

\subsection{Dispersion strengthened copper alloys by MA}

Beside the manufacture of dispersion strengthened copper by internal oxidation (Glidcop, ${ }^{21)}$ ) some work dealing with mechanical alloying in order to prepare dispersion strengthened copper was carried out. ${ }^{22,23)} \mathrm{A}$ comparison between the in-situ formation of $\mathrm{TiC}$ dispersoids in mechanically alloyed $\mathrm{Cu}-\mathrm{Ti}-\mathrm{C}$ powders and the mechanically alloyed $\mathrm{Cu}$-TiC powders is given in. ${ }^{17}$ ) The in-situ formation of $\mathrm{TiC}$ during a subsequent thermal treatment of mechanically alloyed powders, described in, ${ }^{16-18)}$ leads to a microcrystalline copper
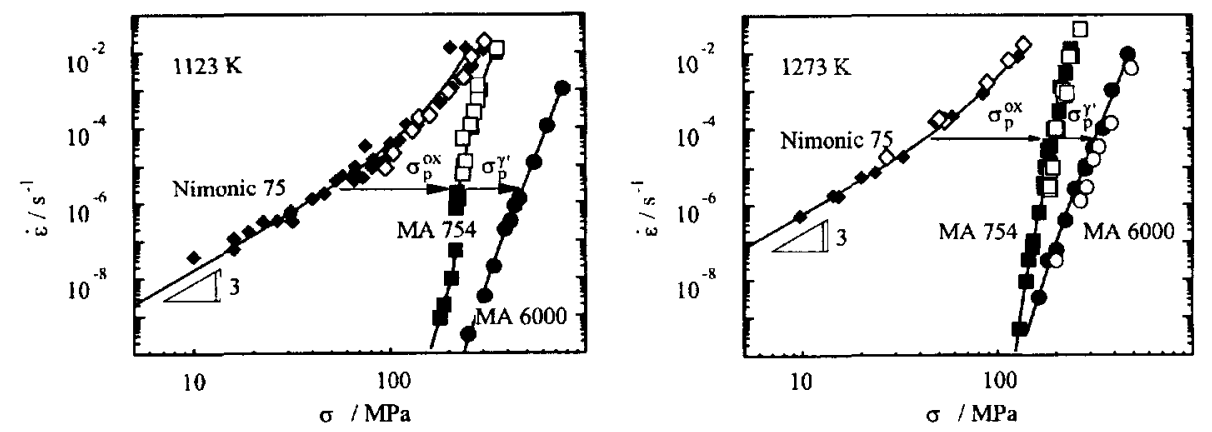

Fig. 2. Strain rate-stress relationship at the point of maximum deformation resistance at $1123 \mathrm{~K}$ (left) and $1273 \mathrm{~K}$ (right). Comparison of the ODS alloys MA754 and MA6000 with their corresponding matrix reference material Nimonic $75,{ }^{19}$ full symbols: tension; open symbols: compression
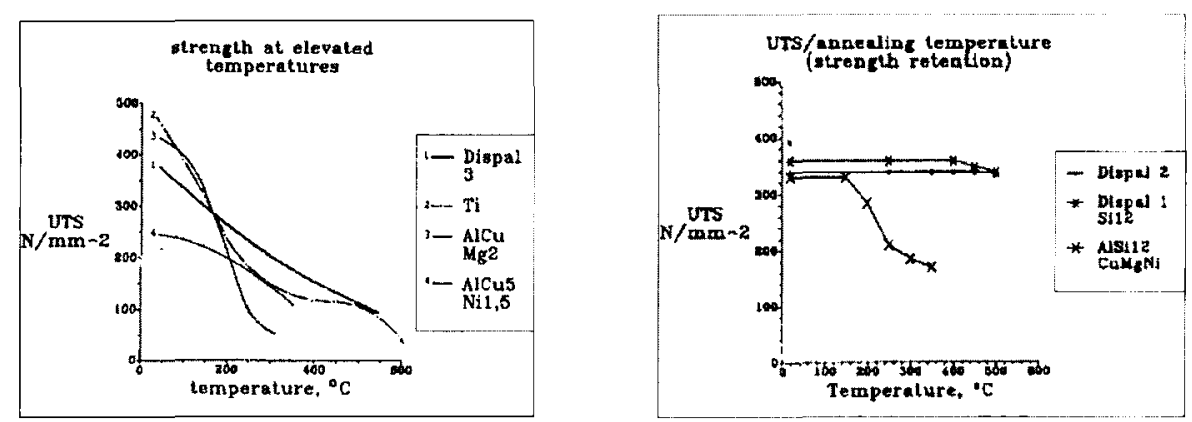

Fig. 3. Strength at elevated temperatures (left) and strength retention after annealing (right) for $250 \mathrm{~h}$ at different temperatures $^{20}$ ) 
matrix with incorporated small TiC dispersoids (Fig. 4). The dispersoids are mainly located on the grain boundaries, but also inside the matrix grains where the TiC dispersoids are considerably smaller but homogeneously distributed. Fig. 5 shows the microstructure of a copper alloy with fine $\mathrm{TiC}$ powder which was milled into the copper using the same milling conditions. It is obvious that the $\mathrm{TiC}$ particle size $\left(\mathrm{d}_{50}=30-40 \mathrm{~nm}\right)$ was not reduced during milling into the soft copper matrix. Consequently the in-situ formation of dispersoids in copper leads to smaller dispersoids and therefore to a smaller copper grain size, too.

The interface between copper and the dispersoids, which is also supposed to have a significant influence on the creep behaviour, was further investigated by

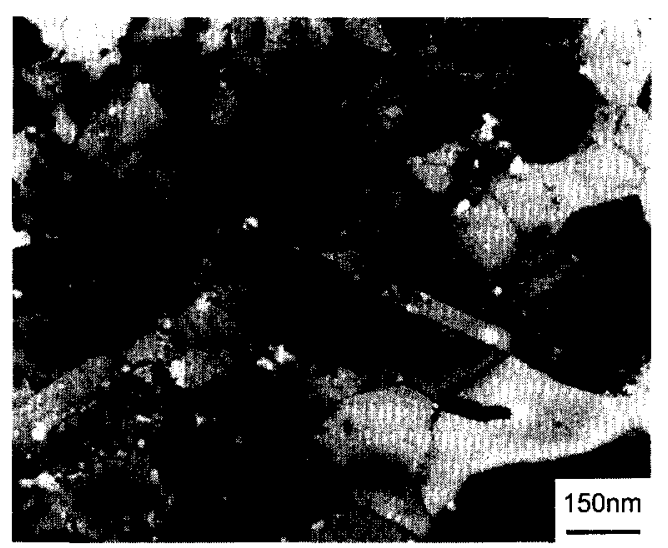

Fig. 4. TEM micrograph of a $\mathrm{Cu}-3$ vol.-\% $\% \mathrm{TiC}_{\text {in-situ }}$ alloy $\left(d_{\mathrm{Cu}} \approx 200 \mathrm{~nm}\right)$.

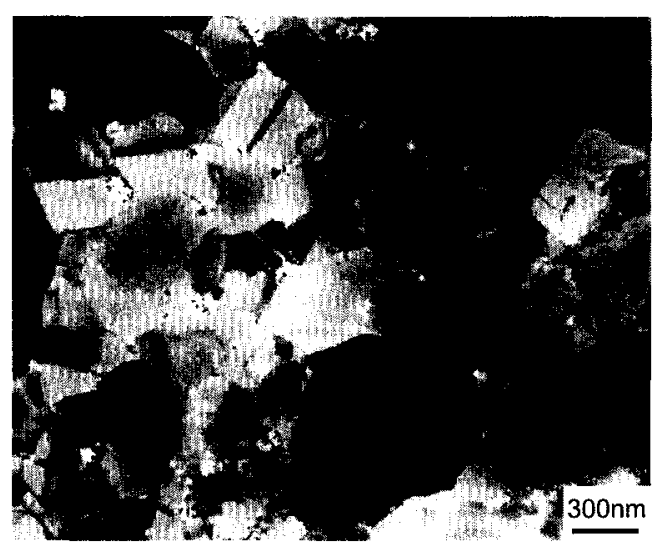

Fig. 5. TEM micrograph of a Cu-3vol.-\% $\% \mathrm{TiC}_{\text {powder }}$ $\operatorname{alloy}\left(d_{\mathrm{Cu}} \approx 400 \mathrm{~nm}\right)$. high-resolution electron microscopy. The in-situ formation of $\mathrm{TiC}$ is governed by an epitaxial growth with (200) and (111) planes of $\mathrm{Cu}$ and $\mathrm{TiC}$ being parallel to each other. ${ }^{24)}$ The misfit of $17 \%$ between (111) TiC and the (111) $\mathrm{Cu}$ planes is accommodated by a periodic array of misfit dislocations located in the copper lattice (arrowed in Fig. 6). The $\mathrm{Cu} / \mathrm{TiC}$ interface is thus semicoherent. The interface between a preformed $\mathrm{TiC}$ dispersoid and the copper matrix is shown in Fig. 7. The interface is seen to be strongly disturbed and incoherent. This is due to the random orientation of the $\mathrm{TiC}$ powder particles in relation to the $\mathrm{Cu}$ matrix after milling.

The room temperature properties of dispersion strengthened copper alloys are shown in Figure 8. It can be seen that the alloys have a considerably higher strength compared to pure copper and an influence of the way the dispersoids are incorporated in the copper matrix exists. The high strength values can be explained by the grain size strengthening (Hall-Petch Relationship) and the particle strengthening mechanism. Particle strengthening is based on the Orowan mecha-

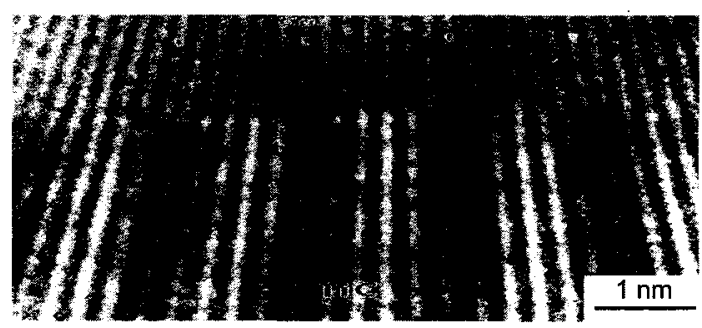

Fig. 6. $\mathrm{Cu} / \mathrm{TiC}_{\mathrm{in} \text {-situ }}$ interface, misfit dislocations in copper (see arrows).

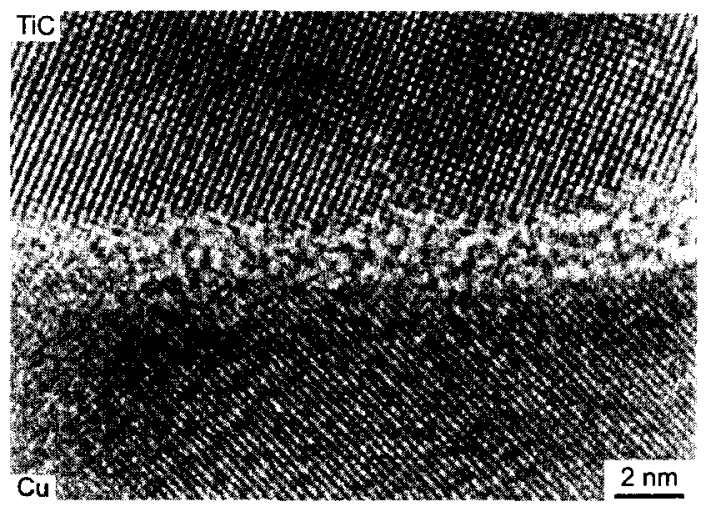

Fig. 7. Interface between a preformed $\mathrm{TiC}$ dispersoid and the copper matrix. 
nism having regard to the elastic anisotropy of the copper matrix. In calculating the Orowan stress a distinction between the dispersoids at the grain boundaries and those in the matrix is necessary. Dispersoids localized at the grain boundaries cannot contribute to the classical Orowan mechanism. For this reason, the Orowan stress was calculated only by considering the dispersoid volume content inside the matrix grains (40 vol. $-\%$ of the total $\mathrm{TiC}$ volume content). The sum of the calculated Orowan stress and the Hall-Petch stress is in good accordance with the experimental values. ${ }^{17)}$

A thermal treatment up to $900^{\circ} \mathrm{C}$ for 1 or $5 \mathrm{~h}$ reveals that the hardness of the dispersion strengthened copper alloys does not change in any way. ${ }^{25)}$ The heat treatment at $1000^{\circ} \mathrm{C}, 1 \mathrm{~h}$ leads to recrystallisation associated with a strong grain coarsening (resulting grain size: $500 \mu \mathrm{m}$ parallel to extrusion axis; $170 \mu \mathrm{m}$ perpendicular to extrusion axis). Due to the coarse grained microstructure the dispersoids that had been localized at the grain boundaries are now inside the matrix. The calculated Orowan stress by considering the total $\mathrm{TiC}$ volume content is in good accordance with the measured yield stress because the Hall Petch stress is negligible now. Due to the larger copper grain size and TiC dispersoid size the strength of the $\mathrm{Cu}+3$ vol.-TiC (powder) is lower compared to $\mathrm{Cu}+3 \mathrm{vol} .-\% \mathrm{TiC}$ (in-situ).

The electrical conductivity of dispersion strengthened copper alloys is $50(\mathrm{Cu}+10 \mathrm{vol} .-\% \mathrm{TiC})$ to $75 \%$ $(\mathrm{Cu}+3$ vol.- $\% \mathrm{TiC})$ and independent of the way the dispersoids are produced.

Fig. 9 shows the effect of the different parameters of the microstructure (grain size, interface dispersoid/ matrix) on the creep strength. It can be seen that the alloy with the in-situ formed $\mathrm{TiC}$ exhibit the best creep strength, the creep strength of the alloy with a

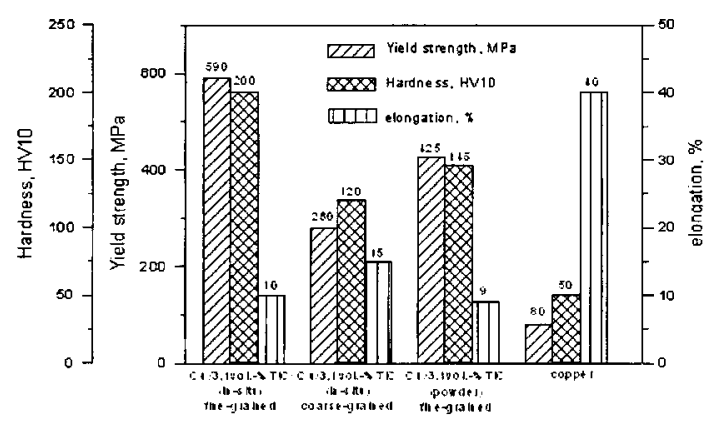

Fig. 8. Room-temperature mechanical properties of TiCdispersion strengthened $\mathrm{Cu}$-alloys. coarse-grained matrix being superior to that with a fine-grained matrix. It is striking that the alloys with $\mathrm{TiC}$ powder have very low creep strength which is even lower than that of pure coarse grained copper. Fig. 10 shows the dependence of the creep rate on the flow stress. The stress exponent $\mathrm{n}$ displays values $>14$; in contrast, pure metals and alloys exhibit $n$ values between 1 and 2 (in the case of diffusional creep) or between 3 and 5 (in the case of dislocation creep). The high stress exponent $\mathbf{n}$ of the coarse-grained alloy with the in-situ formed $\mathrm{TiC}$ results from the fact that in these alloys dislocation creep is the dominant mechanism and the numerous fine dispersoids in the matrix

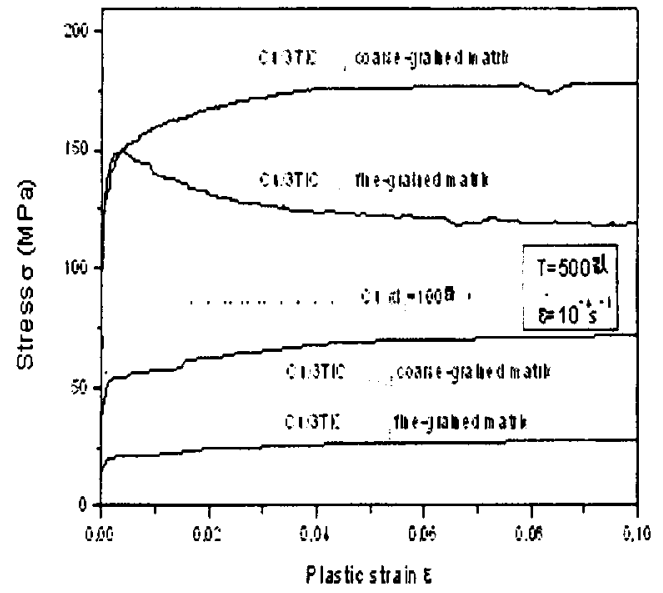

Fig. 9. Creep strength of different $\mathrm{TiC}$ dispersion strengthened copper alloys.

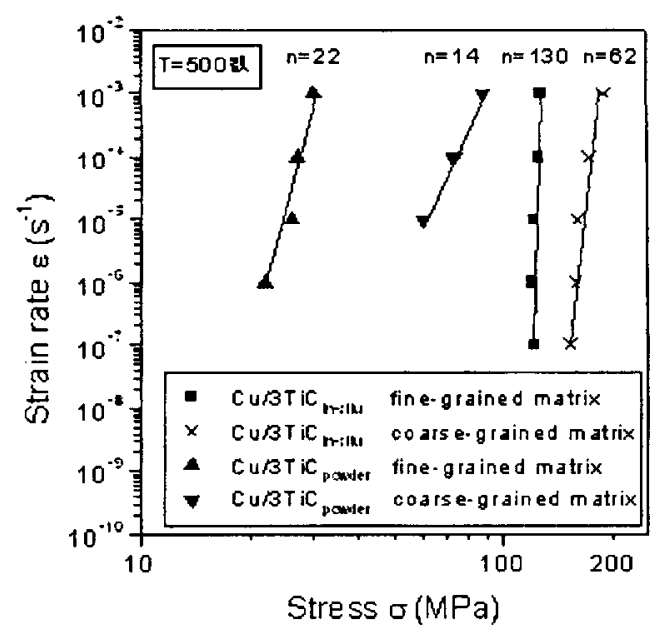

Fig. 10. Dependence of the creep rate on the flow stress $\sigma$. 
prevent the dislocation movement according to the model of Rösler-Arzt. ${ }^{26)}$ On the other hand, the very good creep strength of the microcrystalline alloy with the in-situ formed $\mathrm{TiC}$ dispersoids is very surprising. An explanation for the high stress exponent and the high creep strength is that grain boundary sliding caused by diffusional creep is prevented by the numerous dispersoids on the grain boundaries and thermally activated dislocation detachment is the rate controlling deformation mechanism. A modelling of the creep behaviour was done in. ${ }^{17)}$ Unlike these alloys with insitu formed $\mathrm{TiC}$ dispersoids, the microcrystalline alloys with preformed $\mathrm{TiC}$ exhibit only a very low creep strength and a low stress exponent. This is due to the different interface dispersoid/matrix. While the semicoherent interface of the in-situ formed TiC dispersoids (Fig. 5) very strongly prevent grain boundary sliding, the incoherent interface of the preformed TiC dispersoids to the copper matrix (Fig. 6) hardly offers any resistance to grain boundary sliding. Therefore, in the case of microcrystalline alloys with preformed $\mathrm{TiC}$, the dominant creep mechanism is the interface reaction controlled diffusional creep. ${ }^{17,27)}$

\section{Conclusions}

The technical breakthrough for dispersion strengthened materials came in the form of mechanical alloying (MA) process discovered by Benjamin. The MA process overcame the metallurgical problems associated with the incorporation of nanometer-sized dispersoids and the restrictions in the material selection. The process allows also the use of reactive elements such as $\mathrm{Al}$ and $\mathrm{Ti}$ to produce the full range of oxide-dispersion strengthened (ODS) superalloys. Moreover, the MA process has led to the production of other materials, such as dispersion strengthened light alloys ( $\mathrm{Al}$ based), dispersion strengthened copper and silver, including the synthesis of alloys (e.g. intermetallics) or composite materials.

Our investigations have shown that copper materials with good electrical conductivities in combination with high strength at room and elevated temperature strength can be developed by including finest TiC dispersoids into a copper matrix. The processing technique used allows the production of dispersoids of different sizes and to localize them preferably at grain boundaries.

Investigations into creep behaviour of dispersion strengthened copper demonstrate that alloys with microcrystalline matrix - as they appear immediately after manufacturing - can possess a very good creep resistance if the dispersoids are predominantly located on the grain boundaries - provided the dispersoids have a semicoherent interface to the matrix preventing grain boundary sliding. Such an interface can be obtained if the dispersoids are formed in-situ during thermal treatment. By using preformed TiC dispersoids, the microcrystalline alloys only have an extremely low creep strength.

\section{References}

1. C. S. Smith: Mining and Metallurgy, 11 (1930) 213.

2. R. Irman: Techn. Rundschau (Bern), 36 (1949) 9.

3. E. Orowan: Discussion Symposium on Internal Stresses in Metals and Alloys, Monograph and Rept. Series No. 5, Institute of Metals, London, (1948) 451.

4. L. M. Brown and R. K. Ham: in "Strengthening Methods in Crystals" (eds. A. Kelly, R.B. Nicholson), Elsevier Amsterdam, (1971) 9.

5. G. B. Alexander: US Patent No. 2,972,529, Feb. 21 (1961).

6. G. B. Alexander: US Patent No. 3,019,103, Jan. 30 (1965).

7. J. S. Benjamin: Metall. Trans., 1 (1970) 2943.

8. J. S. Benjamin: Scientific American, 234 (1976) 40-48.

9. J. S. Benjamin and T. E. Vollin: Metall. Trans., 5 (1974) 1929.

10. P. S. Gilman, J. S. Benjamin and Ann. Rev.: Materi. Sci., 13 (1983) 279

11. J. S. Benjamin: in Proc. "New Materials by Mechanical Alloying Techniques" (eds. E. Arzt, L. Schultz), Oct. 1988, DGM Informationsgesellschaft, Oberursel, 1989.

12. G. Jangg, G. Korb and F. Kutner: Proc. of the $6^{\text {th }}$ Int. Leichtmetalltagung, Al-Verlag, Duisseldorf (1975) 61.

13. G. Jangg, F. Kutner, G. Korb: Aluminium 51 (1975) 641.

14. G. Jangg, F. Kutner, G. Korb: Powder Met. Int. 9 (1977) 24.

15. G. Jangg: in Proc. "New Materials by Mechanical Alloying Techniques" (eds. E. Arzt, L. Schultz), Oct. 1988, DGM Informationsgesellschaft, Oberursel, 1989.

16. T. Weißärber, W. Gruner, S. Oswald, G. Dehm, C. Sauer, B. Kieback: in: Proceedings of the $\mathrm{PM}^{2} \mathrm{TEC}$ World Congress on Powder Metallurgy and Particulate Materials, Juni 1996, Washington D.C. (USA).

17. T. Weißärber, PhD thesis: TU Dresden, 1998.

18. T. Weißärber, C. Sauer, B. Kieback: Wissenschaftliche Zeitschrift der TU Dresden 46 (1997) 1. 
19. M. Heilmaier, B. Reppich: Metallurgical and Mat. Trans. A, Vol. 27A, Dec. (1996) 3861-3870.

20. V. Arnhold, K. Hummert: in Proc. "New Materials by Mechanical Alloying Techniques" (eds. E. Arzt, L. Schultz), Oct. 1988, DGM Informationsgesellschaft, Oberursel, 1989.

21. A.V. Nadkarni: Copper-Based Alloys, In: Ochiai, S.: Mechanical Properties of Metallic Composites, Marcel Dekker Inc., New York, Basel, Hong Kong, 1994.

22. C. Peuker; F. Hauner: Patent DE 19532629 C1.
23. W. Nickel, C. Peuker, H.C. Neubing, J. Satdler, R.F. Singer: Werkstoffwoche 1998, Symposium 8ab, München 1998.

24. C. Sauer, T. Weißärber, G. Dehm, J. Mayer, B. Kieback: Z. Metallkd. 89 (1998) 2, 119-125.

25. T. Weißärber; C. Sauer; B. Kieback: Proc. of $14^{\text {th }}$ Int.Plansee Sem., Reutte, (1997) 85-99.

26. J. Rösler, E. Arzt: Acta metall. 38 (1990) 671-683.

27. J. Rösler; R. Joos; E. Arzt: Met. Trans. A., Vol. 23A (1992) 1521-1539. 